\title{
The main hazardous characteristics and safety management measures for the flammable liquids
}

\author{
Zhengyang $\mathrm{An}^{1, \mathrm{a}^{*}}$ \\ ${ }^{1}$ Kunming Fire Services Training School, Kunming China \\ a anzhengyang2005@sina.com
}

Keywords: Flammable liquid; Hazardous characteristic; Safety measures

\begin{abstract}
The flammable liquids are highly flammable and have the characteristics of easy flowing diffusion, a relatively large fire hazard. Once the leakage is out of control and the flammable liquids meet fire source, the fire even explosion accidents of explosive gas mixture will happen easily. Based on the analysis of the major hazardous characteristics of the flammable liquids, measures for the safety management were afforded in this paper.
\end{abstract}

\section{Introduction}

Flammable liquids refer to the pure or the mixture of flammable liquids, or the liquid with solid in the solution or suspension system, whose flash point of closed cup test no more than $60^{\circ} \mathrm{C}$ or flash point of open cup test no more than $65.6^{\circ} \mathrm{C}$. Flammable liquids mainly include flammable liquids such as gasoline, paint and varnish etc, and sensitive-back liquid explosives, for example nitroglycerin alcohol solution, as well as the liquid transported at the temperature equal or above its flash point or the liquid emitting inflammable vapors at temperature equal or lower than the highest transportation temperature.

\section{The main hazardous characteristics of flammable liquids.}

High-flammability. The main reasons for the high flammability of flammable liquids are as follows:

(1) As nearly all organic hydrocarbon compounds or their derivatives, the flammable liquids can react with oxygen through violent combustion.

(2) Due to the low flash points, the ignition points of the flammable liquids are also low, which are generally about 1 to $5^{\circ} \mathrm{C}$ higher than the flash points, leading to sustained burning.

(3) With a low boiling point, the flammable liquids can emit flammable vapors easily and further produce the explosive gas mixture.

(4) Since the energy required for the flammable liquids to ignition is extremely small, the flammable liquids can catch fire and even explode easily when meeting the fire source. Most flammable liquids only need about $0.5 \mathrm{MJ}$ to be ignited. For example, the flash point of $\mathrm{CS}_{2}$ is $-30^{\circ} \mathrm{C}$, and the minimum ignition energy for it is just $0.015 \mathrm{MJ}$, while those of methanol are $11{ }^{\circ} \mathrm{C}$ and 0.215 MJ, respectively. The minimum ignition energies of several common flammable liquids are listed in Table 1-1. 
Table 1-1 The minimum ignition energies of several common flammable liquids

\begin{tabular}{cccc}
\hline Lquids & $\begin{array}{c}\text { Minimum ignition } \\
\text { energy (MJ) }\end{array}$ & Liquids & $\begin{array}{c}\text { Minimum ignition } \\
\text { energy (MJ) }\end{array}$ \\
\hline Carbon disulfide & 0.015 & Methyl Acetate & 0.40 \\
Pentane & 0.28 & Methanol & 0.215 \\
Cyclopentane & 0.54 & Monomethyl Ether & 0.33 \\
Cyclohexane & 0.22 & Diethyl Ether & 0.19 \\
Benzene & 0.55 & Acetaldehyde & 0.376 \\
Gasoline & $0.1 \sim 0.2$ & Propionaldehyde & 0.325 \\
\hline
\end{tabular}

Since the flammable liquids are much volatile, the resulting flammable vapor can diffuse to the entire space of the storehouse or the entire space of cargo body and then mix with air. When the concentration reaches the explosive limits, an explosion can happen in case of fire or sparks. The stronger volatility of flammable liquid is, the greater the risk of such an explosion. Meanwhile, these flammable vapors can drift anywhere, or gather in the low-lying, making the storage of flammable liquids more fire hazardous.

Flow diffusivity. Generally, the inflammable liquids have relatively low viscosity, not only easy to flow by itself, but also easy to exude to the outside of the container with tiny crack because of permeability, infiltration, and capillarity effect. This can enlarge the liquid surface area and increase flammable vapor concentration in the air. Thereby, the risk of explosion combustion increases. If storage vessel bursts, inflammable liquids will flow everywhere, resulting in the rapid expansion of burned area and the rapid spread of fire, which brings more difficulties to fire fighting and rescue work. Therefore, it is necessary to set up accidents groove, fire dike and well in the storage places to protect inflammable liquids from flowing and diffusing.

The lower the viscosity of liquid is and the stronger the fluidity. On the contrary, the fluidity is weaker. Liquid with a larger viscosity is influenced more by temperature. The viscosities of some common flammable liquids at $20^{\circ} \mathrm{C}$ are listed in Table 1-2.

Table 1-2 The viscosities of some common flammable liquids at $20^{\circ} \mathrm{C}$

\begin{tabular}{lcllll}
\hline Liquids & $\begin{array}{l}\text { Viscosity } \\
(\mathrm{MPa} \cdot \mathrm{s})\end{array}$ & Liquids & $\begin{array}{l}\text { Viscosity } \\
(\mathrm{MPa} \cdot \mathrm{s})\end{array}$ & Liquids & $\begin{array}{l}\text { Viscosity } \\
(\mathrm{MPa} \cdot \mathrm{s})\end{array}$ \\
\hline Methanol & 0.584 & Acid & 1.220 & Pentane & 0.229 \\
Ethanol & 1.190 & Propionate & 1.100 & Glycerol & 149.900 \\
Propanol & 2.200 & Butyrate & 2.360 & Turpentine & 1.460 \\
Ether & 0.234 & Benzene & 0.650 & Ethyl Acetate & 0.449 \\
Acetaldehyde & 0.222 & Toluene & 0.586 & Propyl acetate & 0.580 \\
Acetone & 0.322 & Ethylbenzene & 0.670 & Glycol & 19.900 \\
Acid & 1.780 & Xylene & $0.61-0.81$ & Castor oil & 98.600 \\
\hline
\end{tabular}

Heated-expansibility. Inflammable liquid is easy to dilate after heating. At the same time, the vapor pressure is also increased, so the pressure inside the containment vessel increases. Once the pressure inside beyond the pressure limit of vessel, the vessel will dilate and even burst. Drum filling liquid usually bulges and counter made of glass often bursts in summer. So, inflammable liquid should be deposited avoiding heat, leaving with a gap more than 5\%. In summer, flammable liquid should be stored in cool place or sprayed to. The heated volume expansion coefficient values of 
some inflammable liquids are listed in Table 1-3.

Table 1-3 The heated volume expansion coefficient values of some inflammable liquids

\begin{tabular}{cccc}
\hline Liquids & $\begin{array}{c}\text { Volume expansion } \\
\text { coefficient } \beta \text { value }\end{array}$ & Liquids & $\begin{array}{c}\text { Volume expansion } \\
\text { coefficient } \beta \text { value }\end{array}$ \\
\hline Ether & 0.00160 & Pentane & 0.00160 \\
Acetone & 0.00140 & Gasoline & 0.00120 \\
Benzene & 0.00120 & Carbon Disulfide & 0.00120 \\
Toluene & 0.00110 & Acetate & 0.00140 \\
Xylene & 0.00085 & Glycerol & 0.00050 \\
Methanol & 0.00140 & Nitrobenzene & 0.00083 \\
Ethanol & 0.00110 & Phenol & 0.00089 \\
\hline
\end{tabular}

Electrostatic property. Inflammable liquid produces electrostatic because of friction during transporting, filling, shake, mixing and flowing at a high speed in pipe, tank, tanker and oil tanker. When static charges gather to a certain degree, electrostatic spark appears, increasing the risk of combustion explosion. So, some measures for electrostatic protection should be carried out when producing and using inflammable liquid.

No touching with oxidant acid with oxidative. Inflammable liquid can react strongly to produce combustion explosion when touching oxidant or acid with oxidative. Because all inflammable liquids are organic compounds and can react with oxidant and produce large heat, the temperature can rise to kindling point and cause combustion explosion. For example, ethanol burns when touching oxidant potassium permanganate or oxidative acid (concentrated nitric acid or nitric acid). Turpentine burns immediately as soon as touching nitric acid.

Toxicity. Most flammable liquids and steams have different toxicities, even some also have irritation and corrosion. Unsaturated hydrocarbon, aromatic compounds and the volatile oil are more toxic than the saturated hydrocarbon and the nonvolatile oil. The steam of the flammable liquid shows the main toxicity, which can enter human bodies through systems of respiratory, tract and skin to make poison. The degree of poison is combined with both the concentration of the steam and the time of function.

It can reduce and even avoid burn and poison of people in the fire safety inspection or fire rescue process by mastering toxicity and corrosion of flammable liquid, realizing the harm fully and taking the preventive measures

\section{Safety management for flammable liquids}

Siting requirements. The production and storage areas of flammable liquids must be the open field of few people and with safe distance away from the uptowns, facilities and enterprise, reaching the national requirements of the building plan.

Requirements of the safe facilities. Tank farm must be fixed with lighting rod and flameproof light. The storehouse should be ventilated with heat dissipation $\left(15-30^{\circ} \mathrm{C}\right)$, forbidden from fire and sunning, kept rain \& moisture-proof. Facilities and pipelines should be installed with grounding equipment to remove static. In summer, water should be used to cool when the temperature is high. The liquid with a low boiling point should be refrigerated. The function of the plant area function should be programmed reasonably to keep fire passage unblocked, fire water source and fire facility reaching the standard. 
Improved security system. Managers with certificates should well do out-put and in-put registration work of ware house, inspection tour of safe on duty or shifting of duty. All of these must be practiced completely and perfectly.

Storage requirements. Flammable liquid should be stored in a storeroom which is ventilated and cool. The quality of store tank is qualified and reaches the standard in testing quality. Storage tank should be installed firmly or transported easily. The distance between tanks should be in accord with standards. Tanks must not be stored excessively, neither with oxidant, oxidative acid, organic peroxide, self-combustible goods and goods releasing flammable gas when meeting water and explosive goods.

Processing demands in leakage accident. The leakage must be repaired and plugged urgently. Sand can be used to handle the little leakage of liquid,. Otherwise, the leakage of liquid must be recycled.

Requirements of transporting. The liquid must be installed and uninstalled lightly when handling and transporting explosive goods. Dragging, friction, impacting, and rolling are forbidden to avoid leakage and spark. Tools made of iron which are easily producing spark are also forbidden. Operators are forbidden to wear shoes with nails, carry matches and lighters to handling field and smoke.

Transportation requirements. Drivers must have certificates and transport goods according to the time and routes approved by police. It is best to get in or out the storeroom in the morning or evening in hot days. Good grounding device is required to prevent _accumulation of static during transporting, pumping and irrigation. Wooden boat and cement ship to bulk flammable liquid is forbidden.

\section{References}

[1] Jianxun Yang, Jing Yuan, Xin Miao. The fire risk research of using acetone in chemical enterprises[J]. Journal of Chinese People's Armed Police Force Academy, 2010, 26(2): 43-45.

[2] Jie Wang, Wang Zhang, Dong Lv, etc. The semi quantity evaluation of fire risk at places using flammable liquid[J]. Fire Science and Technology, 2010, 29 (1):79-82.

[3] Zhibao $\mathrm{Nu}$, Guofu Liang, Chunxu Yang,etc. The sedimentary regularity of flammable liquid burning pollution in different area of space[J]. Fire Science and Technology, 2011, 30 (9): 860-862.

[4] Tienan Guo. The Chinese fire manual (the Eighth volume)[M]. Shanghai: Shanghai Scientific and TechnicalPublishers, 2013.

[5] Chaogang Tang. The base of safety management of dangerous chemicals[M].Beijing: China Machine Press, 2014.

[6] Qingxian Zhao、Hui Shao、Xiukun Ge. The safety management of dangerous chemicals[M]. Beijing: China Petrochemical Press, 2010.

[7] Hualong Su. The safety management of dangerous chemicals. Beijing: Chemical Industry Press, 2006.

[8] Ruiwen Zhen. Fire protection of dangerous chemicals[M]. Beijing: Chemical Industry Press, 2002. 